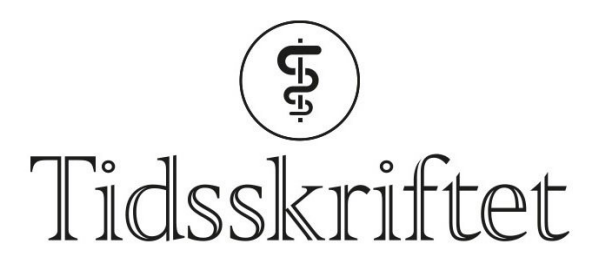

DEN NORSKE LEGEFORENING

\title{
Sint nikkedukke - nevrologisk syndrom i en kriminalroman
}

ESSAY

\section{PETTER STR ØMME}

E-post: petter.stromme@medisin.uio.no

Petter Strømme er overlege ved Barnenevrologisk avdeling, Oslo universitetssykehus, Ullevål og professor emeritus ved Universitetet i Oslo. Han er medlem av Den norske nevrolitterære klubb. Forfatteren har fylt ut ICMJE-skjemaet og oppgir ingen interessekonflikter.

Kriminalromanen The Angry Puppet Syndrome handler om hemmelige forbindelser mellom farmasøytisk industri, akademia, rettsvesenet og offentlig forvaltning. Boken tar utgangspunkt i den sjeldne legemiddelbivirkningen intermitterende eksplosiv lidelse, en hjerneorganisk adferdsforstyrrelse.

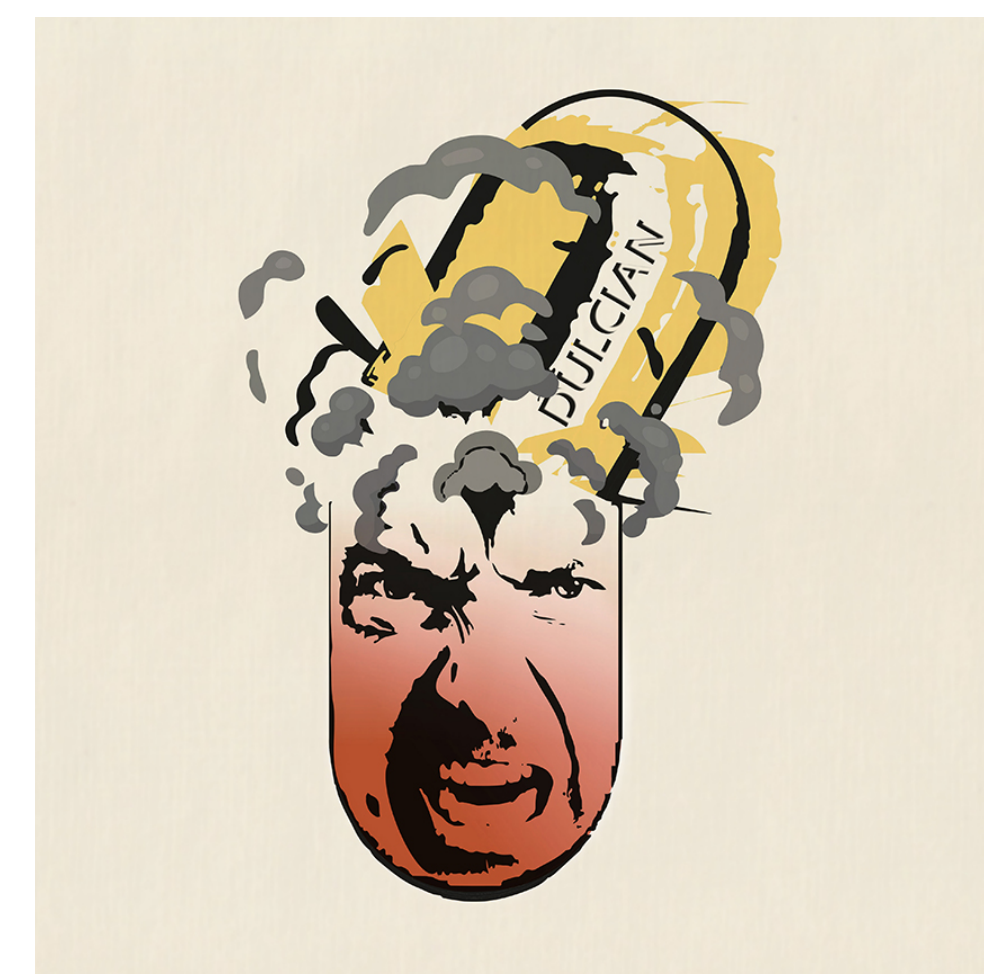

Figur 1 Den oppdiktede Dulcian-tabletten. Illustrasjon: Mariken Lie

John H. Menkes (1928-2008) ble født i Østerrike i en jødisk familie og utvandret til USA fra Irland etter den andre verdenskrigen. Han tok først en grad i organisk kjemi før han utdannet seg til lege ved Johns Hopkins University i Baltimore, Maryland. Han interesserte seg for både psykologi, psykiatri og nevrologi. Etter hvert ble han en nestor i 
barnenevrologi.

Menkes studerte særlig metabolske sykdommer og beskrev i detalj to slike: maple syrup urine disease (OMIM\# 2486oo) - en defekt i aminosyremetabolismen - og Menkes' sykdom (OMIM\# 309400), som skyldes en defekt i koppermetabolismen og som regnes som en prototyp på sjelden genetisk sykdom hos barn (1). I 1974 kom Menkes' Textbook of Child Neurology (2), som senere er revidert og utgitt til sammen sju ganger (3). Menkes engasjerte seg i spørsmål om bivirkninger av vaksinasjon og opptrådte gjerne som ekspertvitne for pasienter som mente seg utsatt for vaksinasjonsskade $(4,5)$. Ved sin bortgang ble han hedret med et minneord av World Federation of Neurology (6).

\section{Sint nikkedukkesyndrom}

Menkes interesserte seg for kunst og litteratur og utga flere romaner og skuespill. The Angry Puppet Syndrome fra 1999 er en kriminalroman som utspiller seg i et universitets- og sykehusmiljø i Los Angeles-området med forgreninger til farmasi- og advokatmiljøer på USAs østkyst (7). Spørsmålene som Menkes tar opp i denne oppdiktede historien, er fortsatt aktuelle, og den nevrobiologiske forklaringen på syndromet i boktittelen er fremdeles gjenstand for vitenskapelig diskusjon. En gjenfortelling av historien og noen utdrag fra boken, i min egen oversettelse, kan kanskje hjelpe leseren til å forstå hva det handler om:

Boken starter med en pasientkonsultasjon hos nevrolog Dan Lerner ved Southwestern University, Los Angeles. Han hadde fått pasienten henvist fra en privatpraktiserende kollega som dr. Lerner ringer opp. Her får han vite at pasientens kone sammenligner personlighetsforandringene hos ektefellen med noe som liknet en sint nikkedukke (angry puppet) (7, s. 8). Cerebral CT, MR og EEG har vært normale. De blir enige om at verken epilepsi, multippel sklerose eller aids passer klinisk. Dr. Lerner forteller at det sannsynligvis er lite han kan bidra med, men lover å følge opp pasienten. 


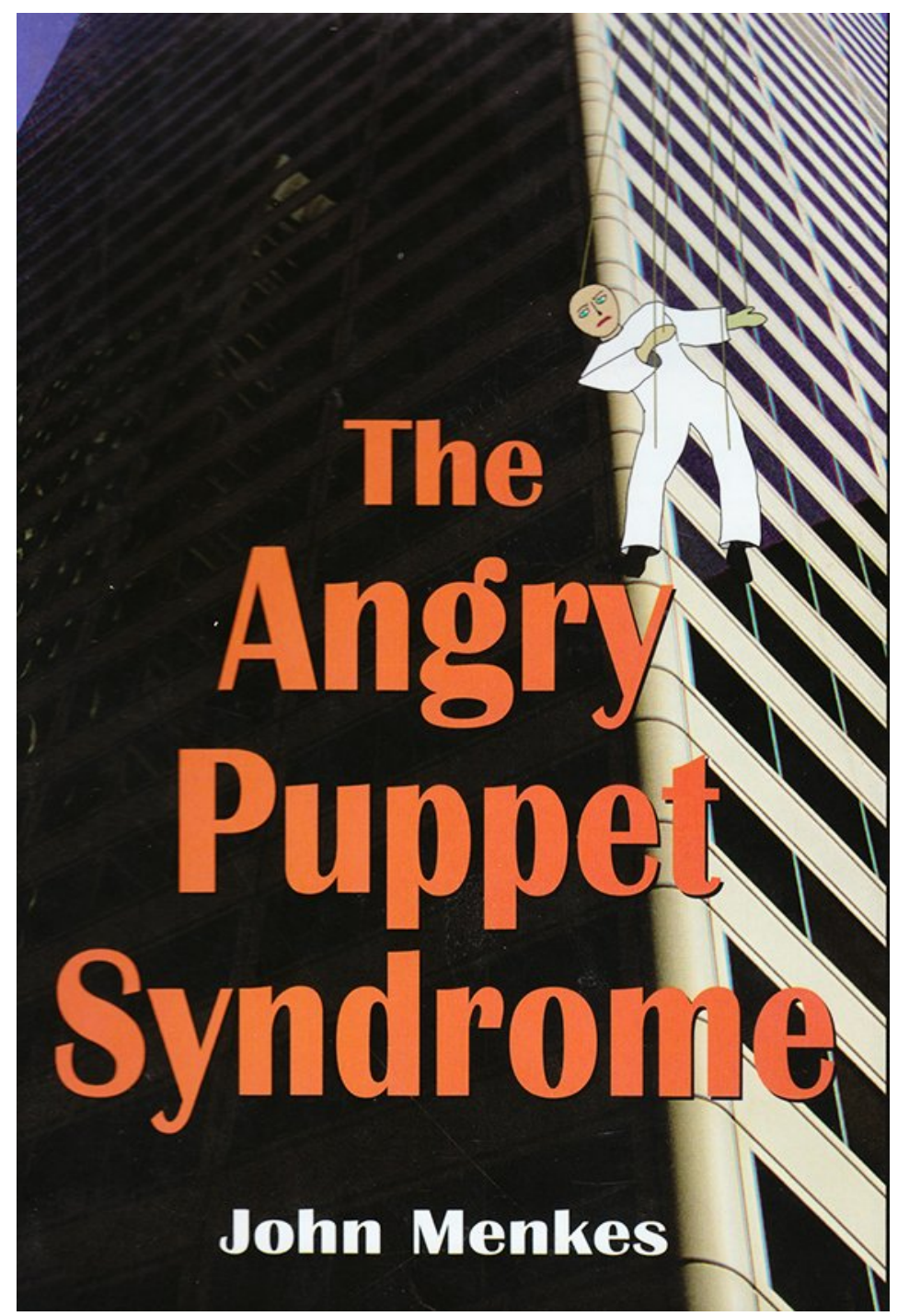

Aktuell bok: John H. Menkes. The Angry Puppet Syndrome. New York: Demos Medical Publishing, 1999.

Uttrykket angry puppet syndrome - som på norsk kan oversettes til sint nikkedukkesyndrom gir assosiasjoner til utviklingsforstyrrelsen puppet syndrome, senere kalt happy puppet, eller Angelmans syndrom (OMIM\# 105830), etter Harry Angelmans beskrivelse av tre pasienter med dukkelignende adferd (8). Angelmans syndrom kjennetegnes blant annet av emosjonelle utbrudd, særlig i form av latter, som i likhet med angry puppet har en nevrobiologisk forankring i de limbiske strukturer.

Som Dan Lerner hadde forventet, var klinisk nevrologisk undersøkelse av den nyhenviste pasienten, Arnold Barton, normal. Men paradoksalt nok provoserer dette Barton, som får et raserianfall (7, s. 17-18). Først beskylder han kona for å «kontrollere» ham, så kaster han skoen sin og dernest stolen i gulvet mens øynene blir ufokuserte og bevegelsene blir som styrt av usynlige strenger. Han river ut kleshengeren som er festet til døren over seg, og skal til å slå til kona, men stivner plutselig til og kaster kleshengeren med en rykkvis bevegelse $\mathrm{i}$ gulvet. Med fråde om munnen, blek og svettende og med en mekanisk stemme skjeller han ut både sin kone og Dan. Så tar han på seg skoen, retter opp stolen og sier unnskyld til sin kone. Han blør fra en finger som ble skadet da han rev ut kleshengeren, men enser ikke skaden. Dan spekulerer i etterkant om det han har vært vitne til, kan ha vært et epileptisk anfall eller personlighetsforstyrrelsen episodisk dyskontroll. Han kommer frem til at sistnevnte diagnose er den mest sannsynlige (7, s. 19; ovenstående avsnitt bygger på ordrett oversettelse).

Menkes lar sin protagonist Dan Lerner stille diagnosen episodisk dyskontroll, en betegnelse på ukontrollerbare sinneutbrudd utløst etter minimal provokasjon (9). Begrepet episodisk dyskontrollsyndrom ble først anvendt av Menninger \& Mayman i 1956 (10), men har senere 
blitt synonymt med intermitterende eksplosiv lidelse, som er en egen diagnose i både DSMkodeverket (11) og ICD-10 (F63.8). Psykiateren Kenneth Nunn hevder at lidelsen skiller seg fra andre former for aggressiv adferd (12). Intermitterende eksplosiv lidelse kan noen ganger forveksles med epilepsi utgått fra temporallappen (13). Allerede i Menkes' første lærebok omtales aggressivitet som manifestasjon på psykomotorisk epilepsi (2), noe han lar Dan Lerner overveie som differensialdiagnose i romanens tilfelle av sint nikkedukkesyndrom.

Andre viktige figurer i persongalleriet er Dan Lerners kjæreste, Maureen Durrell ved Cosgrove \& Costello advokatkontor, direktør dr. Jack Brennan ved Southwestern University, og "vidunderbarnet», den lovende dr. Marty DiChiro (tabell 1). Brennan har ansatt DiChiro på svært gode økonomiske betingelser for å bygge opp en PET-avdeling for adferds- og hypotalamusforskning. Pengene til dette har Brennan fått fra Wallace Foundation. Bak pengegaven ligger det imidlertid et oppdrag fra herr Wallace om å forske på «episodisk dyskontroll», et medfødt uhelbredelig personlighetstrekk som har rammet Wallaces sønn.

\section{Tabell 1}

Personer og institusjoner i The Angry Puppet Syndrome (7).

\begin{tabular}{|ll|}
\hline Person & Rolle \\
\hline Dr. Dan Lerner & Nevrolog, Southwestern University, Los Angeles \\
\hline Arnold Barton & Dan Lerners første pasient med sint nikkedukkesyndrom \\
\hline Maureen Durrell & Advokat og Dan Lerners kjæreste \\
\hline Dr. Jack Brennan & Nevrolog og direktør ved Southwestern University \\
\hline Dr. Marty DiChiro & $\begin{array}{l}\text { Nevrolog og forsker på hypotalamusrelaterte adferdsforstyrrelser } \\
\text { ved Southwestern University }\end{array}$ \\
\hline Wallace Foundation & Sponsor for forskningen til Marty DiChiro \\
\hline Marat International & $\begin{array}{l}\text { Stort farmasøytisk selskap som produserer antidepressivumet } \\
\text { Dulcian }\end{array}$ \\
\hline
\end{tabular}

Menkes formidler på denne måten to forskjellige typer årsaker til intermitterende eksplosiv lidelse, en medfødt og en ervervet. Syndromet kan ha både psykogene og organiske årsaker og forekommer både hos barn og voksne (14).

Dan Lerner spekulerer på hvorfor en veltilpasset person i 50-årene som pasient Arnold Barton har utviklet episodisk dyskontroll og oppfører seg som en «sint nikkedukke». Kan det henge sammen med nylig gjennomgått infeksjon (7, s. 19) eller medikamentet mot lett depresjon, som pasienten for noen måneder siden hadde startet med (7, s. 44-5)?

Medikamentet som Barton har brukt, heter Dulcian og er nytt på markedet (figur 1). Fordi indikasjonen var lett depresjon, kan det forskrives av allmennlege uten henvising til spesialist og dermed nå et stort antall brukere. For produsenten, Marat International, fremstår Dulcian som en potensielt stor inntektskilde, men det gjenstår én viktig hindring, nemlig overvåking av mulige bivirkninger som ledd i fase 3 av den kliniske utprøvningen. Som sin ekspert på bivirkninger har produsenten, med Jack Brennans godkjennelse, hyret dr. Marty DiChiro. Dessverre, nedlesset i arbeid og i økonomisk skvis, ignorerer DiChiro rapporter om foruroligende psykiske reaksjoner på det nye legemiddelet.

Dan Lerner kommer etter hvert i kontakt med tre nye pasienter med samme syndrom som også har brukt Dulcian. Selv om de slutter med medisinen, viser adferdsforstyrrelsen seg som irreversibel, og utfallet for alle fire blir enten at de tar sitt eget liv, for eksempel ved å hoppe ut av vinduet (se omslaget), eller de blir drept som gjengjeldelse for sine voldshandlinger.

Et særtrekk hos pasientene i boken er uttalte tegn til selvskading. I en virkelig studie i 2008 av 376 pasienter med intermitterende eksplosiv lidelse forekom selvpåførte skader og suicidalfors $ø \mathrm{k}$ hos henholdsvis $16 \%$ og 12,5\% (15). Behandling er vanskelig, men haloperidol, litium og propranolol har vært rapportert å ha god effekt $(16,17)$. Kognitiv adferdsterapi, 
både individuelt og på gruppenivå, har også vist godt resultat (18). Nevrokirurgisk behandling har vært sporadisk nevnt, men har ikke vært gjenstand for vitenskapelige studier.

Dan Lerner vil skrive en artikkel basert på de fire kasuistikkene og kaller den «The Angry Puppet Syndrome: An Unusual Adverse Response to Dulcian». Sjefen, Jack Brennan, påstår imidlertid at manuskriptet er uvitenskapelig. Han forbyr publisering og truer med at det kan gå ut over Dans ansettelse (7, s. 69-71, 74). Dan holder på sitt og etter et kryptisk avslag fra New England Journal of Medicine blir artikkelen trykket i Journal of Clinical Neuropsychology. Etter dette blir mange nye tilfeller identifisert. Det dannes en nasjonal pasientforening for syndromet. Foreningen krever erstatning fra Marat International, som tilbyr forlik med 400 ooo dollar (7, s. 181).

Tilbudet avslås og Maureen fører saken mot Marat. Sammen med Dan oppdager de at alvorlig bivirkning av Dulcian ble underslått i første kliniske utprøvning og at den forfalskede rapporten var skrevet av ingen ringere enn dr. Jack Brennan, som da var ansatt hos Marat. Selskapet hadde hele tiden visst om og selv anslått at alvorlige psykiske bivirkninger forekom hos 1 av 5 ooo Dulcian-brukere (7, s. 295).

Marat føler seg presset og hever sitt tilbud om forlik til 85 millioner dollar (7, s. 295). Dette blir godtatt, og saken avsluttes uten at det blir avsagt dom. Dulcian trekkes stille og rolig fra markedet mens Marat Internationals verdi på børsen faller fra 6,17 til 6,10 dollar per aksje (7, s. 296), en kurskorreksjon selskapets direktører er fornøyd med, omstendighetene tatt $i$ betraktning. Selskapet har flere lovende medikamenter under utprøvning. Det ender bra for de fleste aktørene. Maureen blir medeier i advokatfirmaet og gifter seg med Dan Lerner. Marty DiChiro får jobb i et japansk farmasøytisk selskap, der han skal overvåke utprøvningen av et nytt antidepressivum med enda bedre egenskaper enn Dulcian.

\section{Basert på virkeligheten?}

Menkes arbeidet ved Cedars-Sinai Medical Center i Los Angeles da han skrev The Angry Puppet Syndrome, så det er rimelig å tenke at denne institusjonen var modellen for Southwestern University. I boken lar alle seg kjøpe: leger, forskere og universitet samt U.S. Food and Drug Administration (FDA). Det rettes også mistanke mot medisinske tidsskrifter, slik som New England Journal of Medicine, med sin hemmelige forbindelse til FDA. Ifølge Menkes går universitetssykehusenes oppdragsforskning, eksemplifisert med Wallace Foundation, på bekostning av fri forskning, som blir avhengig av usikker støtte fra National Institutes of Health. Universitetsadministrasjonen er autoritær og korrupt og tar imot penger for prosjekter de ikke burde engasjere seg i. Det er dessuten nedslående at «heltene», representert ved Dan Lerner og Maureen Durrell, lar seg kjøpe til taushet. Den lovende Marty DiChiros juks blir aldri oppdaget og han får attpåtil ny og enda bedre betalt jobb i et konkurrerende selskap.

Et særtrekk hos pasientene i boken er uttalte tegn til selvskading

Menkes uttalte i et intervju at The Angry Puppet Syndrome egentlig handlet om hans erfaringer med advokater og farmasøytisk industri i saker om komplikasjoner ved kikhostevaksinasjon (5). Analogien mellom vaksinasjon og medisinering mot depresjon er at sjeldne og alvorlige bivirkninger kan feiltolkes som tilfeldige, slik at produsenten ikke erkjenner ansvar. Samtidens eksperter ble imidlertid aldri enige om sammenhengen av encefalopati etter kikhostevaksinasjon (19). Denne vaksinen har blitt stadig bedre og har ikke skapt debatt i den senere tid (20).

I likhet med Menkes, og på samme tid, kritiserte også den danske samfunnsøkonomen, forfatteren og parkinsonpasienten Hans-Erik Lystrup farmasøytisk industri. I kriminalromanen Parkinsonmysteriet manipuleres den kliniske utprøvningen av en medisin som millioner av pasienter med Parkinsons sykdom verden over kunne ha nytte av (21). Men resultatene av utprøvningen må holdes skjult, og i begge bøkene engasjeres det 


\section{Nyere forskning}

Menkes brukte intermitterende eksplosiv lidelse som en modell på en hjerneskade som kan påføres pasienter. Skaden ble relatert til en nevrokjemisk forstyrrelse, eksemplifisert ved at $25 \%$ av fors $\emptyset$ ksmusene i boken fikk lavt serotoninnivå ved inntak av medikamentet Dulcian (7, s. 169). Serotoninets rolle ved impulsiv aggresjon er ennå ikke klarlagt (22). Den anatomiske lokaliseringen av intermitterende eksplosiv lidelse har vært lite diskutert i litteraturen. Vi må anta at Menkes mente at hypotalamus spilte en sentral rolle (7, s. 58), men det er lite forskning som har støttet dette.

I boken lar alle seg kjøpe: leger, forskere og universitet samt U.S. Food and Drug Administration

En kasuistikk fra 2016 om en kvinne med livslang episodisk dyskontroll tyder på at fasciculus uncinatus kan spille en viktig rolle (figur 2). Etter et kraftig slag mot hodet forsvant det uheldige personlighetstrekket hos kvinnen (23). Det posttraumatiske forløpet ble dokumentert med en validert skala for personlighetsendring (24), mens detaljert billedfremstilling av hjernen over tid viste atrofi av fasciculus uncinatus (særlig høyre fasikkel). Fasciculus uncinatus forbinder prefrontal og temporal korteks via det limbiske system. Myeliniseringen av denne nervebunten skjer svært langsomt og er ikke ferdig før personen er i 3o-årene, og psykososiale faktorer kan virke inn (25). Fasciculus uncinatus' mikrostruktur og myelinisering spiller en viktig rolle for patofysiologiske mekanismer relatert til forskjellige former for angst og emosjonell instabilitet (26).

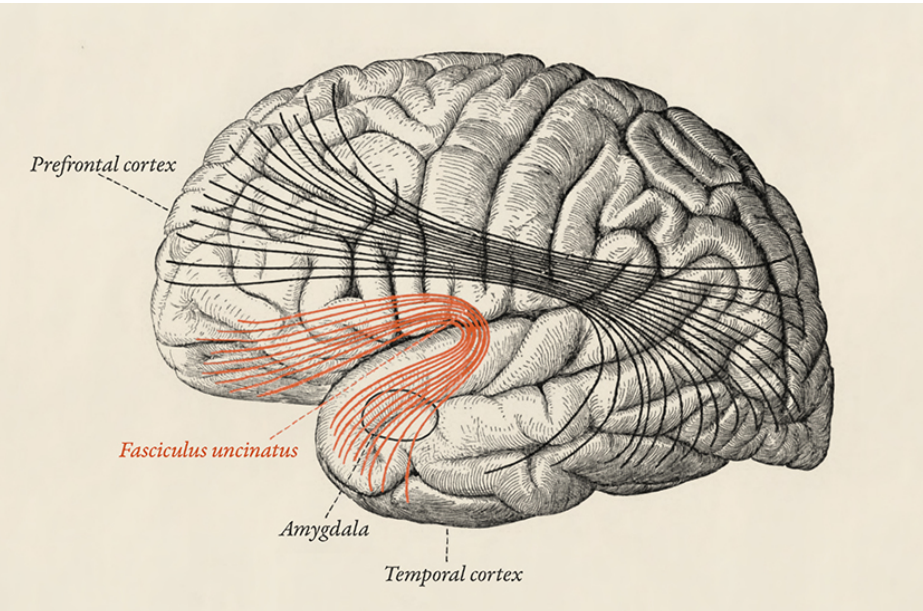

Figur 2 Fasciculus uncinatus er den siste banen $i$ hjernen som myeliniseres, en prosess som ikke er ferdig før personen er i midten av 30-årene. Illustrasjon: Sobotta's Atlas and Text-book of Human Anatomy utgitt i 19o9, tilpasset av Tidsskriftet.

\section{Konklusjon}

Selv om sint nikkedukkesyndrom bare eksisterer i romanen til Menkes, relaterer syndromet seg til en faktisk nevrologisk tilstand - intermitterende eksplosiv lidelse. Denne må han antakelig ha hatt kjennskap til gjennom sin lange karriere som psykiater og barnenevrolog. Senere års forskning indikerer at denne spesielle forstyrrelsen har en nevrobiologisk forklaring, kanskje særlig lokalisert til fasciculus uncinatus, som i likhet med Menkes' hypotalamushypotese, kommuniserer med det som løselig kalles det limbiske system (27).

Menkes brukte sin erfaring som forsker, sykehusadministrator og juridisk-medisinsk ekspertvitne til å bygge opp den fiktive historien om en sjelden, men særdeles alvorlig medikamentbivirkning, som den farmasøytiske industrien med sine økonomiske motiver prøvde å skjule. 


\section{LITTERATUR:}

1. Lee CE, Singleton KS, Wallin M et al. Rare genetic diseases: Nature's experiments on human development. iScience 2020; 23: 101123. [PubMed][CrossRef]

2. Menkes JH. Textbook of Child Neurology. Philadelphia: Lea \& Febiger, 1974.

3. Menkes JH. Textbook of Pediatric Neurology. Philadelphia: Lea \& Febiger, 1985.

4. Menkes JH, Kinsbourne M. Workshop on neurologic complications of pertussis and pertussis vaccination. Neuropediatrics 1990; 21: 171-6. [PubMed][CrossRef]

5. American Academy of Neurology. Up close and personal with John H. Menkes, MD pediatric neurologist, novelist, and playwright. NeurologyToday 2003; 3:1-45.

https://journals.lww.com/neurotodayonline/Fulltext/2003/1200o/Up_Close_and_Personal_With_Joh n_H__Menkes,_MD_.11.aspx Lest 13.1.2021.

6. Snodgrass SR. John Menkes (1928-2008). World Neurology 2009; 24:14. https://worldneurologyonline.com/wp-content/uploads/2013/o3/WFN-June-20o9-Issue.pdf Lest 13.1.2021.

7. Menkes JH. The Angry Puppet Syndrome. New York, NY: Demos Medical Publishing, 1999.

8. Angelman H. «Puppet children». A report on three cases. Dev Med Child Neurol 1965; 7: 681-8. [CrossRef]

9. Elliott FA. Neurology of aggression and episodic dyscontrol. Semin Neurol 1990; 10:303-12. [PubMed][CrossRef]

10. Menninger K, Mayman M. Episodic dyscontrol: a third order of stress adaptation. Bull Menninger Clin 1956; 20: 153-65. [PubMed]

11. Diagnostic and Statistical Manual of Mental Disorders. Fith Edition. Washington, DC: American Psychiatric Association, 2013. https://www.psychiatry.org/psychiatrists/practice/dsm Lest 13.1.2021.

12. Nunn K. The episodic dyscontrol syndrome in childhood. J Child Psychol Psychiatry 1986; 27: 439-46. [PubMed][CrossRef]

13. McTague A, Appleton R. Episodic dyscontrol syndrome. Arch Dis Child 2010; 95: 841-2.

[PubMed][CrossRef]

14. Gordon N. Episodic dyscontrol syndrome. Dev Med Child Neurol 1999; 41: 786-8.

[PubMed][CrossRef]

15. McCloskey MS, Ben-Zeev D, Lee R et al. Prevalence of suicidal and self-injurious behavior among subjects with intermittent explosive disorder. Psychiatry Res 2008; 158: 248-50. [PubMed][CrossRef]

16. Campbell M, Cohen IL, Small AM. Drugs in aggressive behavior. J Am Acad Child Psychiatry 1982; 21: 107-17. [PubMed][CrossRef]

17. Grizenko N, Vida S. Propranolol treatment of episodic dyscontrol and aggressive behavior in children. Can J Psychiatry 1988; 33: 776-8. [PubMed][CrossRef]

18. McCloskey MS, Noblett KL, Deffenbacher JL et al. Cognitive-behavioral therapy for intermittent explosive disorder: a pilot randomized clinical trial. J Consult Clin Psychol 20o8; 76: 876-86.

[PubMed][CrossRef]

19. Cowan LD, Griffin MR, Howson CP et al. Acute encephalopathy and chronic neurological damage after pertussis vaccine. Vaccine 1993; 11: 1371-9. [PubMed][CrossRef]

20. Cherry JD. The 112-year odyssey of pertussis and pertussis vaccines-mistakes made and implications for the future. J Pediatric Infect Dis Soc 2019; 8:334-41. [PubMed][CrossRef]

21. Lystrup HE. Parkinsonmysteriet. Göteborg: Warne Förlag, 2003.

22. Coccaro EF, Fanning JR, Phan KL et al. Serotonin and impulsive aggression. CNS Spectr 2015; 20: 295-302. [PubMed][CrossRef]

23. Coutinho G, Miele F, Moll J et al. Remission of lifelong episodic dyscontrol after bilateral dorsolateral temporal lobe damage. Neurocase 2016; 22: 339-45. [PubMed][CrossRef]

24. Barrash J, Anderson SW, Jones RD et al. The Iowa ratings scales of personality change: Reliability 
and validity. J Int Neuropsychol Soc 1997; 3: 27-8.

25. Linke JO. The Uncinate Fasciculus in Anxiety Disorders: A Potential Treatment Target? Biol Psychiatry 2019; 86: e47-8. [PubMed][CrossRef]

26. Tromp DPM, Fox AS, Oler JA et al. The relationship between the uncinate fasciculus and anxious temperament is evolutionarily conserved and sexually dimorphic. Biol Psychiatry 2019; 86: 890-8. [PubMed][CrossRef]

27. Brodal P. Sentralnervesystemet. Bygning og Funksjon. Oslo: Per Brodal og Tano A.S., 1995.

Publisert: 22. mars 2021. Tidsskr Nor Legeforen. DOI:10.4045/tidsskr.20.0729

(C) Tidsskrift for Den norske legeforening 2020. Lastet ned fra tidsskriftet.no 